\title{
Health and culture: A critical analysis based on studies conducted on older Asian-New Zealanders
}

Jed Montayre

\begin{abstract}
New Zealand is an ethnically diverse nation. The number of overseas-born New Zealanders are increasing and migration pathways have added to the cultural diversity of New Zealand's population. Acknowledging the health complexities experienced by older adults belonging to diverse cultural backgrounds is a growing research interest. This article aims to discuss the specific overlays between health and culture in the case of older Asian-New Zealanders by unpacking, presenting and critically analysing selected New Zealand studies. Based on this critical analysis, health-seeking behaviours and engagement with the healthcare system in New Zealand were influenced by cultural beliefs, traditional family values and the use of mainstream language. Understanding the overlaps between health and culture of the ageing ethnic groups is complex yet useful for health institutions. Furthermore, understanding the perspectives of ageing among ethnic and migrant groups within the context of cultural diversity is enhanced by considering an ethno-specific approach.
\end{abstract}

Keywords: health \& culture, older Asian-New Zealanders, ethno-specific ageing

Jed Montayre is a nursing lecturer at AUT School of Clinical Sciences- Nursing Department and a gerontology researcher at AUT Centre for Active Ageing.

For correspondence: jed.montayre@aut.ac.nz

\section{Introduction}

The number of overseas-born New Zealanders are on the rise and migration pathways have added to the diversity of New Zealand's population (Statistics New Zealand, 2013). New Zealand's current demographic make-up suggests a future of heterogeneous older adults who identify themselves as belonging to particular ethnicities and cultural backgrounds (Statistics New Zealand, 2015a). Population projections have indicated that the number of older adults aged 65 years old and over will reach 1.37 million in 2041, which includes the fast-growing and ageing ethnic populations of Asian New Zealanders (Statistics New Zealand, 2013). The population of older Asians in New Zealand is projected to double by 2025 (Statistics New Zealand, 2009). Globally, there is a noticeable upward trend in ageing ethnic groups, particularly due to late-life immigration (Warnes, Friedrich, Kellaher, \& Torres, 2004; Warnes \& Williams, 2006).

New Zealand is one of the major destination countries for immigrants globally, which explains its multi-ethnic population. Immigrants from Asia, particularly those from China have been in New Zealand since the 1860s (Ip, 2005) and this migration trend continues with individuals coming from different Asian countries. In 2013, there were approximately 471,708 people living in New Zealand who identified as Asians (Statistics New Zealand, 2013). Of the total Asian-New Zealander population, almost $10 \%$ were 60 years old and over. The largest number of older adult population from Asian ethnicities were Chinese, Indian and Filipinos (Statistics New Zealand, 2015a). The relocation and immigration of older adults have implications for the host society's socio-economic and health policies (Ciobanu, Fokkema, \& Nedelcu, 2017). 
Understanding the health complexities experienced by older adults belonging to specific cultural backgrounds is a growing research interest (Al Abed, Davidson, \& Hickman, 2014), further emphasising the need to examine the strong interplay of migration, ethnicity and culture to health and ageing.

There is a strong relationship between ethnicity, culture and health. For example, older Chinese in Canada identified the relationship of health beliefs to their physical health problems (Lai, Tsang, Chappell, Lai, \& Chau, 2007). Additionally, a New Zealand study found a predictive association between acculturation and mortality advantage in different ethnic groups (Hajat, Blakely, Dayal, \& Jatrana, 2010). In New Zealand, efforts to accommodate cultural differences in relation to health services have been established. An initiative to deliver best and quality healthcare experiences for the culturally and linguistically diverse population has been established at district health board levels (Lim \& Mortensen, 2013). There is also increasing attention on surveillance and reporting of health issues in Asian communities (Scragg, \& Maitra, 2005; Scragg, 2016). The health needs of Asian-New Zealanders' have been identified with distinct cultural variations from the mainstream population (Rasanathan, Ameratunga, \& Tse, 2006). However, available evidence from nationally-commissioned health reports and statistical health data do not provide information on the specific culturally-associated factors of varying health outcomes and behaviours. Mingsheng (2013) in a New Zealand study found that acculturation impacts on older Chinese' general wellbeing and quality of life, and encompasses relationships with adult children, filial responsibilities, living arrangements and other socio-cultural factors. The findings serve as the precursor of this article in furthering the discussion towards health and wellbeing issues within the cultural context of older Asians in New Zealand. This discussion paper accommodates a focussed cultural lens on health among older Asian-New Zealanders and provides insights to healthcare professionals such as nurses, general practitioners (GP), rehabilitation teams and social workers.

This article aims to discuss the specific overlays between health and culture in the case of older Asian-New Zealanders by unpacking, presenting and critically analysing examples from selected New Zealand studies of older Asians.

\section{Search Strategy}

A critical case analysis of published New Zealand studies focussing on older AsianNew Zealanders was undertaken. A literature search was conducted using online databases such CINAHL, PubMed, PsycINFO, Scopus, Web of Science and Google Scholar. Search terms applied were 'older Asians in New Zealand', 'Late-life immigrants', 'Asian health' and 'health and culture'. While there is growing research on older Asians in New Zealand, I purposively included studies that were strongly relevant to the aim of this discussion paper, which was to identify specific interpretations from available New Zealand literature. The inclusion criteria are following: (1) published articles focusing on the influence of culture on health-related outcomes and behaviour for older Asian New Zealanders living in New Zealand; (2) published full-text articles in English or with retrievable English version. Articles were excluded if the focus did not align with the cultural and health contexts of older Asian-New Zealanders or if the articles did not include older Asians (60 years old and over).

\section{Themes}

Culturally-Based Health Beliefs 
In New Zealand, the differences between the diverse older Asian ethnic groups and the mainstream populations were observed in terms of the influence of cultural beliefs on health-seeking behaviours. Cheung's (2010) profiling of older Chinese referrals and admission to mental health services in New Zealand indicated a higher incidence of serious clinical presentations due to delays in seeking care. Cheung (2010) found these delays and ineffective health-seeking behaviours among older Chinese could be traced back to common Asian cultural beliefs of mental illness as a "supernatural punishment of wrong-doings and entails intense stigma and shame" (p. 156). This particular cultural belief presents a different perspective from the mainstream views of mental illness. The cultural beliefs surrounding physical and mental health have a significant impact on the promptness of seeking health services and older Asians' willingness to engage with prescribed treatment regimen.

Another specific example involves older Korean-New Zealanders' experience of 'Hwabyung', a culture-related anger syndrome resulting from family members' mistreatment and enduring frustrations as a consequence of late-life immigration in New Zealand (Park, 2014). In Park's (2014) discussion 'Hwa-byung' was described as the repression of anger and unpleasant emotions causing physical or somatic symptoms, which affected the general health and mental well-being of older Korean New Zealanders. Similar to Cheung's (2010) inference about ineffective health seeking behaviours of older Chinese, Park (2014) presented 'Hwa-byung' as a culturally-associated barrier in seeking help and appropriate mental health services. Park (2014) acknowledged Min, Suh, and Song's (2009) work on 'Hwa-byung' and puts forth the argument that this particular anger syndrome is exclusively unique to Korean culture, which has a strong affiliation to Confucian values of respect for filial piety and close family relationships. This Asian-based family values would have been compromised as a result of late-life immigration.

\section{Language, Cultural Values and Health Organizations' Policies}

In a recent study of older Filipinos in New Zealand, problems such as language barriers and the unfamiliarity of healthcare policies challenged cultural values. These were noted as compounding factors to difficulties in engaging with the New Zealand healthcare system (Montayre, Neville, \& Holroyd, 2017). Older Filipinos spoke of their experiences with health services as limiting their traditional and cultural practices. In Montayre et al. (2017), an older Filipino woman shared her experience of being unable to stay overnight with her daughter who had just given birth due to the hospital's policy of visiting hours. Older Filipinos' desires to assume the culturally-based caregiver role for a sick family member by staying in the hospital were seen to be conflicting with clinical policies like infection control. It was noted that these conflicts occur due to the influence of the biomedical model within hospital policies. On the other hand, communication difficulties were experienced by one older Filipino participant, who felt discriminated against by nurses who assumed she could not speak English (Montayre et al., 2017).

\section{Discussion}

There is growing interest in Asian-New Zealanders' health and well-being. However, there is a paucity of studies focussing on the older Asian-New Zealander population. The main argument of this discussion paper is centred on the interplay between culture and health identified among older Asians in the New Zealand population. The 2013 New Zealand Census recorded that 23 percent of Auckland residents identified themselves belonging to Asian ethnicity (Statistics New Zealand, 2013). Some Asian New Zealanders are late-life immigrants (Statistics New Zealand, 2015b), who did not have enough time for them to acculturate and integrate within New Zealand society.

Based on the examples presented, health-seeking behaviours and engagement with the healthcare system in New Zealand for older Asians were greatly influenced by 
cultural beliefs, traditional family values and the use of the English language. Culturally-based health beliefs with some religious or spiritual significance was found to strongly influence the older person. Cultural beliefs can become a barrier to prompt diagnosis and potentially delay the process of seeking relief. This delay can have serious life-threatening consequences. A similar cultural pattern is common in a few developing countries where health visits are strongly associated with health literacy (Irwan et al., 2016).However, in New Zealand, specific cultural beliefs that have inferences to stigma and shame, require further investigation to mitigate delayed consultation, particularly in mental health.

Beliefs and emotional responses specific to certain cultures should not be underestimated. Culturally-based responses and reactions should prompt health professionals to perform 'focussed assessments' with their clients. The 'anger syndrome' (Min, Suh, \& Song, 2009; Park, 2014) referred to earlier, specific to older Koreans is a prime example. Awareness of this cultural response involving emotional suppression is critical as it impacts on health seeking behaviour and should prompt interventions. Similarly, a study from the United States revealed the strong correlation of culturally-specific emotional responses amongst older Koreans to high levels of depression. The study by Jang, Kim, and Chiriboga, (2005), suggest cultural influences in expressing emotional response, and propose improving our understanding of divergent cultural expression and health beliefs. Emotional suppression, fuelled by cultural expectations of having to deal with one's problems and emotions independently, was also noted among Japanese people and provides some insight into the suicide incidence rates among older Japanese in rural areas (Traphagan, 2004). It is noted, however, that older Asians in New Zealand have exerted arduous efforts to adjust to the cultural differences in their new adopted society and to re-establish identity caused by disrupted social connections due to late-life immigration (Montayre et al., 2017).

The conflict between traditional cultural practices and health organisations' policies is one aspect noted from the selected New Zealand based studies (Montayre et al., 2017). While New Zealand promotes culturally-safe practice among individual healthcare practitioners, the acknowledgement of specific and culturally diverse practices of clients and their families can be easily overlooked within organisational policies and procedures. This is due in part to the lack of awareness of cultural diversity and the push for generic protocols within healthcare organisations, which do not clearly outline cultural differences. For example, older Filipinos felt this conflict and expressed being hindered from assuming a culturally-based role of nurturing their sick or hospitalised family member (Montayre et al., 2017). Adhering to hospital policies around visiting hours and maintaining infection control by preventing overcrowding in rooms were the areas noted by a group of older Filipinos. Older Filipinos found these experiences as barriers for them to fulfil their familial obligations and caregiving roles. These familial roles are central to the Filipino cultural values (Miralao, 1997). While these situations also occur among non-Asian ethnic groups, these complexities are more prominent among Asian families due language issues and the expectations to follow regulations as 'model or good immigrants' in host countries (Maneze et al., 2016; Tzu-Chun Wu, 2017). Situations where conflict arose between cultural practices and health organisation protocols were common, particularly in cases of visiting the hospitalised family member. The constraints older Filipinos experienced with visiting family members and having overcrowding policies in the hospital room is similar to Asian-Islamic immigrant women in the US, where restrictions imposed through hospital procedures on visitations created a culture-care conflict (Rashidi \& Rajaram, 2001). Rashidi and Rajaram (2001) emphasised that visitations from family members were considered very important and restrictions could result in "ill-feeling between family members and the patient, leading to social and psychological stress" (p.62). 
The fluent use of English language was also a culture-related issue noted among older Filipinos, which affected their engagement with health professionals during hospitalisation (Maneze et al., 2016). However, older Filipinos' feelings of being ignored (Montayre et al.,2017) were alleviated by having Filipino nurses in the ward who acted as the bridge for the communication difficulties. While utilising healthcare professionals like nurses as interpreters for non-English speaking patients pose great benefits, it should be noted that patients could express their symptoms using 'cultural metaphors' which do not have a Western clinical equivalence (ElderkinThompson, Silver, \& Waitzkin, 2001). This could lead easily to misinterpretation and might require an interpreter who has an in-depth understanding of cultural expression and health. Additionally, assumptions made by healthcare professionals to clients' inabilities to use the English language could be interpreted by clients as discriminatory.

Ageing ethnic groups experience multidimensional complexities (Radermacher, Feldman, \& Browning, 2009; Warnes \& Williams, 2006). In New Zealand, one of these complexities is that the diverse cultural backgrounds, and diverse health beliefs among migrant and ethnic groups can pose as barriers to access health treatment, and service utilisation, thereby creating disparities in health care (DeSouza, 2006; Signal, Martin, Cram, \& Robson, 2008). International research also presented evidence on the strong association between health and culture among ethnic groups (Smith et al., 2013). Although there are multiple realities of how culture relate and influence health and behaviour, having a deeper understanding from specific examples of cultural and health overlays would facilitate wider perspectives of this particular process and deepen understanding of socio-cultural presentations of illness.

\section{Conclusion}

Older Asian New Zealanders' diverse cultural beliefs and unique cultural expressions require further exploration as they pose critical implications for health behaviours and engagement with healthcare services. Understanding the overlays between health and culture in ageing ethnic groups is complex. Factors like the age at immigration, relationship with adult children and families within the host societies, their strongly-held cultural beliefs, their fluent use of mainstream language and the culture of host societies were among the identified complexities that impact their health and wellbeing. Ameliorated efforts towards culturally-targeted health services may be achieved effectively if culturally-sensitive health needs were explicitly identified. The examples from the reviewed articles focusing on older Chinese, Korean and Filipinos in New Zealand suggested that understanding the perspective of ageing among ethnic and migrant groups within the context of cultural diversity could be achieved by explicitly considering an ethno-specific approach.

Healthcare professionals such as GPs, nurses, rehabilitation teams, social workers and care assistants, who provide direct care and social services to older Asian- New Zealanders should consider a holistic culturally-based care approach. A holistic approach extends not only to the management of mental, and physical conditions or symptoms among older Asian-New Zealanders but also recognises that health beliefs are socially and culturally bound. This recognition will give credence to the valuing of a diverse ethnic and cultural society and indeed for the benefit of health care and New Zealand society in the future. Additionally, increasing awareness about cultures or encouraging ethnic representation in the health workforce could help facilitate culturally-targeted care. With New Zealand's growing culturally diverse older people, it is a timely call for further exploration and integration of an ethnic and culturespecific approach to ageing within academic health curricula and New Zealand's health and social services. 
Pacific Health, vol 2, 2019 ISSN 2537-8864 


\section{References}

Al Abed N.A., Davidson P.M., \& Hickman L.D. (2014). Healthcare needs of older Arab migrants: A systematic review. Journal of Clinical Nursing. doi: doi: $10.1111 /$ jocn. 12476

Cheung, G. (2010). Characteristics of Chinese service users in an old age psychiatry service in New Zealand. Australasian Psychiatry, 18(2), 152-157

Ciobanu, R. O., Fokkema, T., \& Nedelcu, M. (2017). Ageing as a migrant: vulnerabilities, agency and policy implications. Journal of Ethnic and Migration Studies, 43(2), 164-181.

DeSouza, R. (2006). Researching the health needs of elderly Indian migrants to New Zealand. Indian Journal of Gerontology, 20(1), 159-170.

Elderkin-Thompson, V., Silver, R. C., \& Waitzkin, H. (2001). When nurses double as interpreters: a study of Spanish-speaking patients in a US primary care setting. Social Science \& Medicine, 521343-1358. doi:10.1016/S02779536(00)00234-3

Hajat, A., Blakely, T., Dayal, S., \& Jatrana, S. (2010). Do New Zealand's immigrants have a mortality advantage? Evidence from the New Zealand census-mortality study. Ethnicity \& health, 15(5), 531-547.

Ip, M. (2005). Chinese. Te Ara - the Encyclopedia of New Zealand. Retrieved from http://www.TeAra.govt.nz/en/chinese (accessed 19 August 2017).

Irwan, A. M., Kato, M., Kitaoka, K., Kido, T., Taniguchi, Y., \& Shogenji, M. (2016). Original Article: Self-care practices and health-seeking behavior among older persons in a developing country: Theories-based research. International Journal of Nursing Sciences, 311-23. doi:10.1016/j.ijnss.2016.02.010

Jang, Y., Kim, G., \& Chiriboga, D. (2005). Acculturation and manifestation of depressive symptoms among Korean-American older adults. Aging \& Mental Health, 9(6), 500-507.

Lai, D. L., Tsang, K. T., Chappell, N., Lai, D. Y., \& Chau, S. Y. (2007). Relationships between Culture and Health Status: A Multi-Site Study of the Older Chinese in Canada. Canadian Journal on Aging, 26(3), 171-183.

Lim, S. \& Mortensen, A. (2013). Best Practice Principles: CALD Cultural Competency Standards and Framework. Waitemata District Health Board [WDHB].

Min, S. K., Suh, S. Y., \& Song, K. J. (2009). Symptoms to use for diagnostic criteria of hwa-byung, an anger syndrome. Psychiatry investigation, 6(1), 7-12.

Mingsheng, L. I. (2013). Acculturation, Filial Responsibilities and Living Arrangements: An Empirical Study of the Acculturative Experiences of Elderly Chinese Immigrants in New Zealand. Intercultural Communication Studies, 22(1).

Miralao, V. A. (1997). The Family, Traditional Values and the Socio-cultural Transformation of Philippine Society. Philippine Sociological Review, 45(1/4), 189-215.

Montayre, J., Neville, S., \& Holroyd, E. (2017). Moving backwards, moving forward: the experiences of older Filipino migrants adjusting to life in New Zealand. 
International Journal of Qualitative Studies on Health and Well-being, 12(1), 1347011.

Maneze, D., Everett, B., Kirby, S., DiGiacomo, M., Davidson, P. M., \& Salamonson, Y. (2016). 'I have only little English': language anxiety of Filipino migrants with chronic disease. Ethnicity \& Health, 21(6), 596-608.

Park, H. J. (2014). Living with 'Hwa-byung': The psycho-social impact of elder mistreatment on the health and well-being of older people. Aging \& mental health, 18(1), 125-128.

Radermacher H., Feldman S., \& Browning C. (2009). Mainstream versus ethnospecific community aged care services: It's not an 'either or'. Australasian Journal On Ageing, 28(2), 58-63.

Rasanathan, K., Ameratunga, S., \& Tse, S. (2006). Asian health in New Zealand: progress and challenges. The New Zealand Medical Journal, 119(1244).

Rashidi, A., \& Rajaram, S. S. (2001). Culture Care Conflicts among Asian-Islamic Immigrant Women in US Hospitals. Holistic nursing practice, 16(1), 55-64.

Scragg, R. Asian Health in Aotearoa in 2011 - 2013: trends since 2002-2003 and 2006-2007. (2016). Auckland: Northern Regional Alliance Ltd.

Scragg, R., \& Maitra, A. (2005). Asian Health in Aotearoa: An analysis of the 2002 / 2003 New Zealand Health Survey. Auckland: The Asian Network Inc.

Smith, A., MacEntee, M., Beattie, B., Brondani, M., Bryant, R., Graf, P., \& ... Wong, S. (2013). The Influence of Culture on the Oral Health-Related Beliefs and Behaviours of Elderly Chinese Immigrants: A Meta-Synthesis of the Literature. Journal of Cross-Cultural Gerontology, 28(1), 27-47. doi:10.1007/s10823-0139187-4

Statistics New Zealand (2009). Ageing of Ethnic Groups (Structural Change and the $65+$ Population articles). Wellington: Statistics New Zealand.

Statistics New Zealand (2013). 2013 Census QuickStats about national highlights. Available from www.stats.govt.nz.

Statistics New Zealand (2015a). 2013 Census QuickStats about people aged 65 and over. Available from www.stats.govt.nz.

Statistics New Zealand. (2015b). International Visitor Arrivals to New Zealand. Wellington, New Zealand: Retrieved from http://www.stats.govt.nz/.

Signal, L., Martin, J., Cram, F., \& Robson, B. (2008). The health equity assessment tool: a user's guide. Wellington: Ministry of Health, 3-20.

Traphagan, J. W. (2004). Interpretations of Elder Suicide, Stress, and Dependency among Rural Japanese. Ethnology, 43(4), 315-329.

Tzu-Chun Wu, J. (2017). The Origins of The Model Minority. Journal of American Ethnic History, 36(2), 99-101.

Warnes, A. M., \& Williams, A. (2006). Older migrants in Europe: a new focus for migration studies. Journal of Ethnic and Migration Studies, 32(8), 1257-1281.

Warnes, A. M., Friedrich, K., Kellaher, L., \& Torres, S. (2004). The diversity and welfare of older migrants in Europe. Ageing \& Society, 24(3), 307-326. 